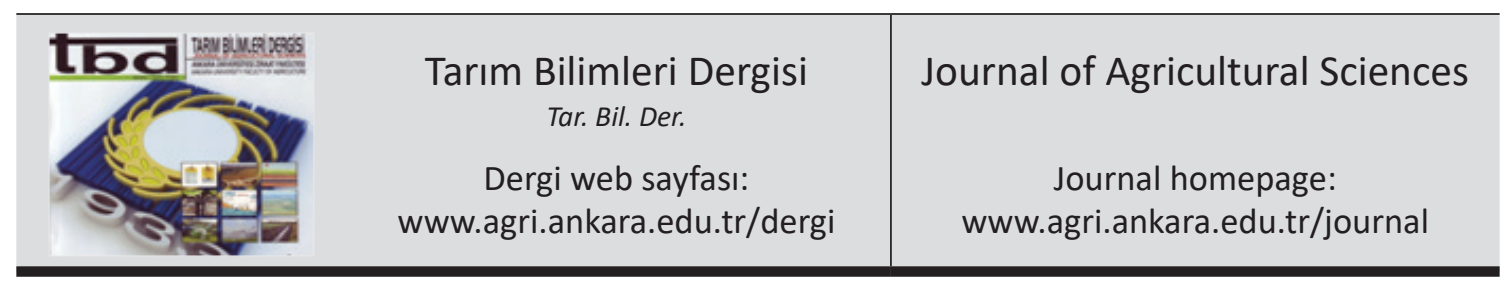

\title{
Tractor Lifetime Assessment Analysis
}

\author{
Zoran MILEUSNIĆa , Miloš TANASIJEVIĆb, Rajko MIODRAGOVIĆa , Aleksandra DIMITRIJEVIĆa, \\ Mirko UROŠEVIĆa \\ ${ }^{a}$ University of Belgrade, Faculty of Agriculture, Department for Agricultural Engineering, SERBIA \\ ${ }^{\boldsymbol{b}}$ University of Belgrade, Faculty of Mining and Geology, SERBIA
}

\section{ARTICLE INFO}

Research Article DOI: 10.15832/ankutbd.403823

Corresponding Author: Zoran MILEUSNIĆ, E-mail: zoranm@agrif.bg.ac.rs, Tel: +381 112194606

Received: 09 March 2018, Received in Revised Form: 28 May 2018, Accepted: 03 June 2018

\begin{abstract}
In this paper, two different approaches in analyzing the tractor lifetime assessment are presented. The first one is based on reliability theory and the other one is based on the relevant experience that was implemented in the ASABE standards. In this way, the dependence of tractor reliability and lifetime on working conditions is presented through two models verified in the paper. Tractors from two different producers were analyzed. Experimental data were collected during the tractor working engagement at the fields of Agricultural Corporation Belgrade (ACB). Analyzing the obtained data it is possible to find the mismanagement in the tractor usage. Removing them it is possible to extend the period of tractor utilization. In this way the overall organization of tractor-machinery system on a farm can significantly be improved.

Keywords: Standards; Tractor; Reliability; Remaining lifetime
\end{abstract}

(C) Ankara Üniversitesi Ziraat Fakültesi

\section{Introduction}

Tractors are one of the most used power units on the agricultural farms. Apart from agriculture, they are used as basic or drive machines in the mining and construction engineering systems. Tractor working environment varies significantly from one place to another so it is very difficult to estimate its influence on the tractor overall lifetime. Calculation of operational life of complex machines, despite designer's effort, is performed using some probability prediction model, which is based on assessment made by experienced designers and analogies with existing machines and experiences gained during their operation, including corrections related to differences of installed equipment. Anyhow, exact calculation of the operational life during design is not possible, hence it is about aspired operational life (Polovina et al 2010). During systems operation, based on the working and maintenance parameters it is possible to accurately define reliability and remaining capability of technical system. It is also possible to define the critical condition when the system does not fulfil its functionality. In Ebramhimipour \& Suzuki (2006), the effectiveness was defined as overall indicator which contains efficiency, reliability and availability. In Miodragovic et al (2012), the effectiveness was defined as total indicator of 
reliability, maintainability and functionality. This is justified concerning the fact that the availability contains reliability and, thus, these two cannot be analyzed separately. Effectiveness, as a parameter, is very suitable for the analysis of technical systems such as tractors. There are new concepts that use money and costs parameters specially the maintenance cost parameters. According to Plessis (2007), there are three models of analyzing the costs and equipment service lifetime relation, with the aim of determining the moment of replacement of earthmoving equipment. These methods include the replacement that is primarily done on intuition, age-based replacement and replacement after performing an economic analysis. A machine must be replaced when a supposed frequency of breakdowns becomes so high that the machine is not reliable any longer. Finally, a machine must be replaced when the costs of repair begin to increase the average unit costs of accumulation beyond the minimum ones. For example, equipment manufacturer - Komatsu, has developed a model for determination of time frame for replacement of mining equipment; for the agricultural machines a model for assessment of remaining lifetime on the base of ASABE standard was developed. In any case, complete overview of the tractor lifetime is required as optimization process that synthesizes the cost and reliability (Previati et al 2011). Agricultural systems demand detailed planning and control of relevant biological, technical, technological and other processes (Mileusnic et al 2010). Among others, machinery statistics represents a crucial information that influences the agricultural technique management. The adequate data basis of this kind is an initial point for the appropriate decision-making. Miodragovic et al (2012) established the model for effectiveness determination according to fuzzy sets theory utilization. There by the fuzzy sets were used to analyze reliability, maintainability and functionality performances (partial indicators of effectiveness) as well as and for their integration into effectiveness. On the basis of data acquired on various Serbian farms (Tomantschger et al
2011), the frequency distribution and probability density function of the engine lifetime (up to the overhaul is done) has been obtained. An original mathematical model, which includes the differential Equation with adequate conditions, has been developed for this purpose. It is clear that all the models have, as their base, the reliability i.e. only with the reliable machines the high performance, low working and maintenance costs can be expected. Dalmiş et al (2017) and Ekinci \& Çarman (2017) dealt with the tractor efficiency problem. Dalmiş et al (2017) analyzed the effects of materials fatigue on the exploitation parameters of three point hitch tractor system, using the method of finite elements. They also analyzed the effects of some drive tires properties on the improvement of tractive efficiency.

The aim of this paper is the use the experimental data from the field for the working productivity and the lifetime assessment analysis. The idea was to use exploitation data of the two tractor models for showing the methods for lifetime assessment analysis; the first one based on the basic model known from the reliability theory, and the other one based on the ASABE standards specially developed for these purposes. In this way, the verification of the models is done between themselves where the first one is strictly theoretical and the other one is specialized for the situation.

\section{Material and Methods}

Reliability engineering is a sub-discipline within system sciences. Reliability within the timedepending systems is defined as a time function $R(t)$ and can have the value between 0 and 1 or between 0 and $100 \%$. Reliability can be also given as the number of successfully finished tasks and the total number of the system tasks ratio. In the case where for every moment of time, a system has all the tasks finished successfully, the reliability is 1 i.e. $100 \%$. In the other case, when $R\left(t_{1}\right)=0$, it can be said that the time $t_{1}$ is the end of lifetime. Essentially, for one system can be said that it is at the end of its lifetime when the failure rate $(\lambda)$ begins to increase rapidly. 
Failure rate can be defined based on the failure function $f(t)$ as:

$\lambda(t)=\frac{f(t)}{R(t)} ; f(t)=\frac{d F(t)}{d t}$

Where; Failure probability (unreliability) represented by the following Equation.

$F(t)=1-R(t)$

Failure rate is the frequency of fails of a technical system or element. Failure rate is often called as the rapidity of failure. Relation between failure rate and lifetime can be presented in form of diagram (Figure 1). With the technical systems that are not fully worked out in the sense of construction and functionality (produced in pieces such as plants etc.) the above mention relation can be described via so called bathtub curve. This curve is characterized by three periods where during the first period system is in the stage of working itself out. During the second period, which is the most time consuming period, systems enters the stationary state. In the third period systems has failures and reaches it lifetime period. For the technical systems that are produced in the large series (tractors, etc.) there is no need for the first period (interrupted line on Figure 1) i.e. these systems are starting their usage in Normal life regime. In this regime the failure rate is low and continues up to end of lifetime where failure rate increases rapidly. If the systems is fully checked during time in sense of recording the periods of failure and based on the probability theory, functions $R(t)$ and $\lambda(t)$ can be determined (3-4). In general, these functions can be used for assessment of remaining lifetime. When solving the problem in the domain of failure theory two-parameter Weibull distribution showed as the most suitable (Weibull 1951). In this distribution, the reliability function and failure rate can be determined by the following equations, respectively

$R(t)=e^{-\left(\frac{t}{\eta}\right)^{\beta}}$

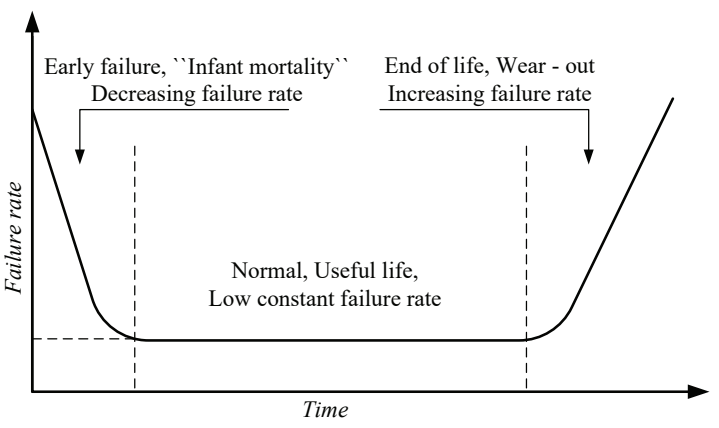

Figure 1- The bathtub curve, hypothetical relation failure rate versus time

$\lambda(t)=\frac{\beta}{\eta} \cdot\left(\frac{t}{\eta}\right)^{\beta-1}$

Where; $\beta$ is shape parameter and $\eta$ is scale parameter.

The mean time to failure (MTTF) was determined with below Equation.

MTTF $=\eta \cdot \Gamma\left(1+\frac{1}{\beta}\right)$

Where; Gamma function $(\Gamma)$ is represented by the following Equations.

$\Gamma(p)=\int_{0}^{\infty} t^{p-1} e^{-t} d t$

$p=1+\frac{1}{\beta}$

Weibull function is used due to its parametric shape and the possibilities of the other distribution laws. For the needs of lifetime management, it is very important to precisely define the moment $t$ when system should be withdrawn from engagement (from work). In Figure 1, this is the moment when failure rate begins to increase rapidly (III period). It is the time period when $R(t)$ function falls down on a certain low point. These two approach are theoretical. In real conditions, technical systems usually have a possibility for some kind of reparation which then complicates these graphical presentations. 


\subsection{Assessment model of remaining lifetime}

Calculation of remaining value $\left(R V_{n}\right)$ as a percentage of the list price for farm equipment at the end of $n$ years of age and after $h$ average hours of use per year using the following equation and the coefficients which depends on the power of the engine on the tractor is shown in Table 1.

Table 1- Remaining value coefficients

\begin{tabular}{llll}
\hline Equipment type & $C_{1}$ & $C_{2}$ & $C_{3}$ \\
\hline Farm tractors & 0.9810 & 0.0930 & 0.0058 \\
\hline TSmall $<60 \mathrm{~kW}$ & 0.9420 & 0.1000 & 0.0008 \\
Medium $60-120 \mathrm{~kW}$ & 0.9760 & 0.1190 & 0.0019 \\
Large $>112 \mathrm{~kW}$ & &
\end{tabular}

$R V_{n}=100\left[C_{1}-C_{2}\left(n^{0.5}\right)-C_{3}\left(h^{0.5}\right)\right]^{2}$

To include the inflation effects, the list price of farm equipment should be multiply by $(1+i)^{\mathrm{n}}$ where $i$ is the average annual inflation rate, $n$ is the age of the machine. Machine effectiveness can be defined as a ratio between machine productivity in the real, field conditions and maximum theoretical productivity (ASABE 2009). The effectiveness in the field conditions includes improper usage of machine in sense of its working width, time losses caused by operator itself and field characteristics (Table 2). Expenditures are necessary to keep a machine operable due to wear, part failures, accidents and natural deterioration. The costs for repairing a machine are highly variable. Good management may keep costs low. Indices of repair and maintenance costs are shown in ASABE (2009). The size of the machine, as reflected by its list price and the amount of use are factors affecting the costs. Both the use and costs are expressed in an accumulated mode to reduce variability. In times of rapid inflation, the list price must be increased to reflect inflation effects. Accumulated repair and maintenance costs at a typical speed can be determined with the following relationships using the repair and maintenance factors $R F 1$ and $R F 2$ (ASABE 2009) and the accumulated use of the machine (ASABE 2006).

$C_{r m}=(R F 1) \cdot P \cdot\left[\frac{h}{1000}\right]^{(R F 2)}$

Where; $C_{\mathrm{rm}}$ is accumulated repair and maintenance cost; $R F 1$ and $R F 2$ are repair factors. $P$ is machine price. During rapid inflation, the original list price must be multiplied by $(1+i)^{n}, h$ is the accumulated hours of machine use.

For the model, two time-digressive amortisation methods were used. The first method is the digital digressive amortization. The lowering of the amortisation quotas that are in the arithmetic sequence, can have a value like the amortisation from the last period of usage.

$a_{k}=\frac{V_{a}}{1+2+\ldots+n} \cdot[n-(k-1)]$

Where; $a_{k}$ is amortisation level in the given periods of lifetime; $V_{a}$ is the based amortization, $n$ is usage period as years, and $k$ is current period.

The second method is the geometrical digressive amortization when amortisation quotes are decreasing as elements of the geometrical sequence.

Table 2- Field efficiency, field speed, and repair and maintenance cost parameters

\begin{tabular}{|c|c|c|c|c|c|c|c|c|}
\hline \multirow[t]{2}{*}{ Machine } & \multicolumn{2}{|c|}{ Field efficiency (\%) } & \multicolumn{2}{|c|}{ Field speed } & \multirow{2}{*}{$\begin{array}{l}\text { Estimated } \\
\text { life }(h)\end{array}$} & \multirow{2}{*}{$\begin{array}{l}\text { Total life } \\
R \& M \text { cost } \\
(\%)\end{array}$} & \multicolumn{2}{|c|}{ Repair factors } \\
\hline & Range & Typical & Range & Typical & & & $R F 1$ & $R F 2$ \\
\hline \multicolumn{9}{|c|}{ ASAE D497.6 } \\
\hline Tractor $4 \times 2$ & - & - & - & - & 12000 & 100 & 0.007 & 2.000 \\
\hline Tractor $4 \times 4$ & - & - & - & - & 16000 & 80 & 0.003 & 2.000 \\
\hline
\end{tabular}


$a_{k}=a_{n} \cdot q^{(n-k)}$

$a_{n}=V_{a} \cdot \frac{q-1}{q^{n}-1}$

Where; $a_{n}$ is amortisation at the end of lifetime period and $\mathrm{q}$ is geometrical sequence ratio.

\section{Results and Discussion}

In this paper, as an illustrative example of agriculture machinery evaluation for lifetime assessment, the comparative analyses of two tractors, Fendt Vario 920 (A-type tractor) and John Deere 8520 (B- type tractor), are contain. Based on their engagement the following data about the time of failure are obtained. Experimental data collected from "ACB" have also taken into account the time of the specific intervention on the every tractor form. In all four cases, the number of collected data was $n<30$, so, for the calculation of cumulative distribution function $F(t)$, Median rank $(M R)$ also known as Bernard's approximation, was used (Table 3). Concerning the fact that these method are well known, only the reliability and failure rate functions are presented, as well as the mean time to failure values from 13 to 16 Equations, for tractors A1, A2, B1 and B2, respectively. The calculations used well-known tools: median rank, probability plotting paper, last square method and Kolmogorov-Smirnov test.
Table 3- Time to failures for observed tractors, hours

\begin{tabular}{|c|c|c|c|}
\hline$A 1$ & $A 2$ & B1 & $B 2$ \\
\hline $\begin{array}{r}F V-920 ; \\
F 28\end{array}$ & $\begin{array}{r}F V-920 ; \\
F 30\end{array}$ & $\begin{array}{l}J D \text { 8520; } \\
\text { Inv. no. } 36\end{array}$ & $\begin{array}{l}J D \text { 8520; } \\
\text { Inv. no. } 37\end{array}$ \\
\hline 6374 & 4766 & 4682 & 4168 \\
\hline 6583 & 4896 & 6682 & 6610 \\
\hline 6840 & 7367 & 8980 & 7631 \\
\hline 8145 & 7685 & 9790 & 9122 \\
\hline 8365 & 8139 & 10493 & 9614 \\
\hline 8636 & 9359 & 10646 & 9630 \\
\hline 9332 & 10380 & 10862 & 9695 \\
\hline 10765 & 14796 & 10865 & 10168 \\
\hline 11349 & & 11051 & 10434 \\
\hline 12276 & & 11717 & 11180 \\
\hline 13476 & & 11981 & 11376 \\
\hline 13670 & & 12210 & 11689 \\
\hline 13745 & & 12470 & 11936 \\
\hline 15369 & & 12563 & 12385 \\
\hline \multirow[t]{7}{*}{16096} & & 12675 & 12634 \\
\hline & & 12743 & 12785 \\
\hline & & 12757 & \\
\hline & & 12836 & \\
\hline & & 13200 & \\
\hline & & 13721 & \\
\hline & & 14023 & \\
\hline
\end{tabular}

Kolmogorov-Smirnov test (K-S) is the most common method for testing of hypothesis of established distribution law. K-S test compare empirical cumulative distribution function and theoretical function $F(t)=1-R(t)$, on the base of their distance $D_{n}$. Necessity is that the distance is less than the critical value $D_{n \alpha}$, and we can conclude that the data is a good fit with the specified

$$
\begin{aligned}
& R(t)=e^{-\left(\frac{t}{11941.94}\right)^{3.55}} ; \lambda(t)=2.97 \cdot 10^{-4} \cdot\left(\frac{t}{11941.94}\right)^{2.55} ; M T T F=10750.55 \text { hours } \\
& R(t)=e^{-\left(\frac{t}{9523.81}\right)^{2.78}} ; \lambda(t)=2.92 \cdot 10^{-4} \cdot\left(\frac{t}{9523.81}\right)^{1.78} ; M T T F=8209.39 \text { hours } \\
& R(t)=e^{-\left(\frac{t}{12273.77}\right)^{4.00}} ; \lambda(t)=3.26 \cdot 10^{-4} \cdot\left(\frac{t}{12273.77}\right)^{3.00} ; M T T F=11124.70 \text { hours } \\
& R(t)=e^{-\left(\frac{t}{11213.06}\right)^{3.80}} ; \lambda(t)=3.39 \cdot 10^{-4} \cdot\left(\frac{t}{11213.06}\right)^{2.80} ; M T T F=10134.96 \text { hours }
\end{aligned}
$$


distribution law. Critical value can be found in the Kolmogorov-Smirnov table. The largest distance in presented case study is for tractor B1 and for data $i=6: D_{n}=0.15976$. For the given example (tractor B1) that contains $n=22$ data, according to K-S test for goodness of fit, the acceptable difference between empirical and theoretical value is: $D_{n ; \alpha}=D_{22 ; 0.05}=0.285$ (O'Connor \& Kleyner 2012). Usually calculated with level of significance $\alpha=0.05$. Since $D_{n}=0.160<0.285=D_{10 ; 0.05}$, we conclude that the data is a good fit with the Weibull distribution. K-S test shows that the actual model is satisfactory accuracy. The simplest parameter for comparing two tractors is mean time to failure (MTTF). Concerning this parameter the $\mathrm{B} 1$ tractor is the best having the mean time to failure of 11124.70 hours. The worst results were obtained for A2 tractor with the 8209.39 hours. Based on the reliability function $(R(t))$ and Figure 2, the same conclusions, about the most reliable tractor can be obtained. For example, if 12000 hours are considered to be a reference time, it can be seen that for tractor B1 there is $40 \%$ probability that it is working properly while with the A2 tractor this probability is $15 \%$. If it is said that probability that a systems works properly is $20 \%$ then tractor B1 will achieve this value after 13800 hours, tractor A1 after 13650 hours, tractor B2 after 12700 hours and tractor A2 after 11300 hours. Based on the failure rate function $(\lambda(t))$ and Figure 3 , it can be concluded that A- type tractor is less susceptible to failure rate increment. In any case it can be seen that failure rate starts to grow in the 12000-15000 hours interval, when $\lambda>0.0005$. Based on the average values of the above parameters it can be generally concluded that B- type tractor is slightly better compared to A- type tractor. Table 4 gives the results obtained for A- type tractor, using the digital digressive amortisation model (according to ASABE standard). Purchasing tractor price was $162000 €$ and the price after the $10^{\text {th }}$ year of usage is $52024 €$. Inflation rate was adopted on the basis of average inflation rate in EU of $1.6 \%$. The prevailing interest rate was $4.4 \%$ while real interest rate was $2.8 \%$. From Table 4 can be seen that, as far for the tractor unit the accumulated costs are starting to grow after the seventh year of usage. For the same tractor geometrical digressive amortisation was used, with the same input parameters. It can be seen that with the given amortisation rate unit accumulation costs are starting to increase in the tenth year of tractor usage. The same trend in the results, according to the both criteria, was observed for the B- type tractor (Tables 3 and 5). Purchasing price of B- type tractor was $155900 €$ and after the ten years of usage the value was $50065 €$. If results of applied ASABE standards and theory of reliability are compared it can be seen that in the case of digital digressive amortisation method they are almost identical. With this model 11200 hours are the point where one should think about replacing the tractor and purchasing the new one. In this moment the unit accumulation costs are starting to increase. Theoretical model states that for the B- type tractor reliability starts to decrease at 11200 hours from $37 \%$ up to $50 \%$ and in the case of A-type tractor the reliability falls to $21 \%$ even down to $45 \%$ meaning that there is a higher probability that tractor is out of function than the probability that operates well. In addition, failure rate is just starting to increase at the value of 12000 15000 hours meaning that right time for tractor replacement should be planned at the interval of 11200 hours. All this indicates that when the time of tractor replacing is in question these methods are compatible. However, the geometrical digressive amortisation method states that the time when unit accumulation costs start to increase is after 16000 hours of tractor usage. The reliability of Atype tractor is between 2 and $6 \%$ while it is $6 \%$ for B- type tractor. For sure this is the time when tractor should be replaced. If not the productivity of tractor it will significantly decrease. Results of the theoretical model show that the B-type tractor is a better solution than A- type concerning the reliability during the period of usage. According to the validation results, all the tractors are still in use. B- type tractor has 16096 working hours and the procedure for its replacement has started. A- type tractor has 14023 working hours and it is still in usage. Hypothesis, on the beginning of the research, was that the lifetime of the equipment depends on technical and economical parameters. The first one can be expressed via availability and reliability and the other one can be expressed 
via economic indicators. Regarding the results tendencies, these two approaches are in accordance. This paper proves it and the case study has served as a proof of the hypothesis on the beginning. Similar results were obtained by Tomantschger et al (2011) applying the different models.

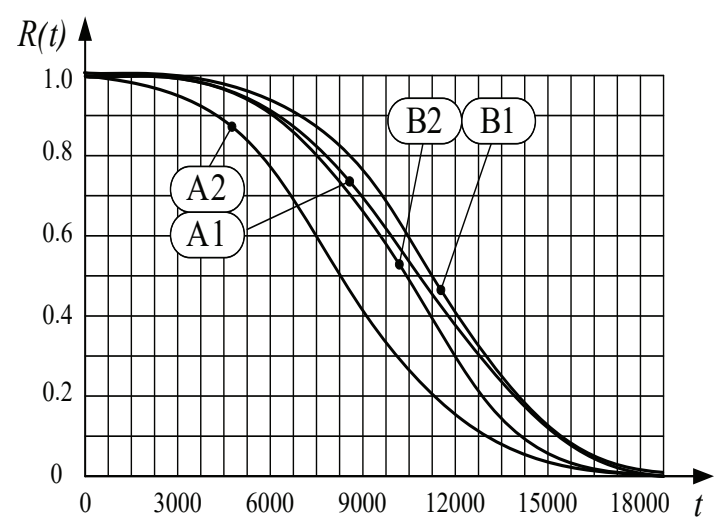

Figure 2- Reliability function

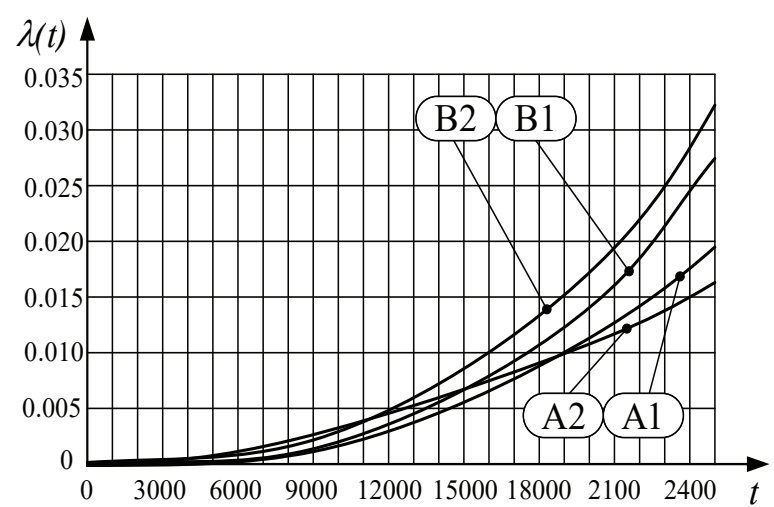

Figure 3- Failure rate function

Table 4- Digital digressive amortization model for A type tractor

\begin{tabular}{crrrrrrrrrr}
\hline $\begin{array}{c}\text { End of } \\
\text { year }\end{array}$ & $\begin{array}{r}\text { Rest of } \\
\text { value } \\
(\epsilon)\end{array}$ & $\begin{array}{r}T_{o} \\
(\epsilon)\end{array}$ & $\begin{array}{r}\text { Amortization } \\
(\epsilon)\end{array}$ & $\begin{array}{r}\text { Interest } \\
(\epsilon)\end{array}$ & $\begin{array}{r}\text { Amortization. } \\
\text { am) }\end{array}$ & $\begin{array}{r}\text { Acum. } \\
\text { interest } \\
(\epsilon)\end{array}$ & $\begin{array}{r}\text { Acum. } \\
T_{o} \\
(\epsilon)\end{array}$ & $\begin{array}{r}\text { Acum. } \\
T_{\text {total }} \\
(\epsilon)\end{array}$ & $\begin{array}{r}\text { Acum. } \\
\text { use } \\
(h)\end{array}$ & $\begin{array}{r}\text { Unit acum. } \\
\text { cost } \\
\left(\epsilon h^{-1}\right)\end{array}$ \\
\hline 1 & 164805 & 1264 & 25063 & 4615 & 25063 & 4615 & 1264 & 30942 & 1600 & 19.34 \\
2 & 142249 & 3873 & 22556 & 3983 & 47619 & 8598 & 5137 & 61354 & 3200 & 19.17 \\
3 & 122199 & 6606 & 20050 & 3422 & 67669 & 12020 & 11743 & 91432 & 4800 & 19.05 \\
4 & 104655 & 9468 & 17544 & 2930 & 85213 & 14950 & 21211 & 121374 & 6400 & 18.95 \\
5 & 89617 & 12462 & 15038 & 2509 & 100251 & 17459 & 33673 & 151383 & 8000 & 18.93 \\
6 & 77086 & 15592 & 12531 & 2158 & 112782 & 19617 & 49265 & 181664 & 9600 & 18.92 \\
7 & 67061 & 18863 & 10025 & 1878 & 122807 & 21495 & 68128 & 212430 & 11200 & 18.96 \\
8 & 59542 & 22280 & 7519 & 1667 & 130326 & 23162 & 90408 & 243896 & 12800 & 19.05 \\
9 & 54529 & 25851 & 5013 & 1527 & 135339 & 24689 & 116259 & 276287 & 14400 & 19.18 \\
10 & 52024 & 29560 & 2506 & 1457 & 137845 & 26146 & 145819 & 309810 & 16000 & 19.36 \\
\hline
\end{tabular}

Table 5- Geometrical digressive amortization model for B type tractor

\begin{tabular}{crrrrrrrrrr}
\hline $\begin{array}{c}\text { End of } \\
\text { year }\end{array}$ & $\begin{array}{r}\text { Rest of } \\
\text { value } \\
(\epsilon)\end{array}$ & $\begin{array}{r}T_{o} \\
(\epsilon)\end{array}$ & $\begin{array}{r}\text { Amortization } \\
(\epsilon)\end{array}$ & $\begin{array}{r}\text { Interest } \\
(€)\end{array}$ & $\begin{array}{r}\text { Acum. } \\
\text { amortization } \\
(\epsilon)\end{array}$ & $\begin{array}{r}\text { Acum. } \\
\text { interest } \\
(\epsilon)\end{array}$ & $\begin{array}{r}\text { Acum. } \\
T_{o} \\
(\epsilon)\end{array}$ & $\begin{array}{r}T_{\text {total }} \\
(\epsilon)\end{array}$ & $\begin{array}{r}\text { Acum. } \\
\text { use } \\
(h)\end{array}$ & $\begin{array}{r}\text { Unit Acum. } \\
\text { cost } \\
\left(\epsilon h^{-1}\right)\end{array}$ \\
\hline 1 & 116328 & 1216 & 66391 & 3257 & 66391 & 3257 & 1216 & 70864 & 1600 & 44.29 \\
2 & 83132 & 3728 & 33196 & 2328 & 99587 & 5585 & 4944 & 110116 & 3200 & 34.41 \\
3 & 66534 & 6357 & 16598 & 1863 & 116185 & 7448 & 11301 & 134934 & 4800 & 28.11 \\
4 & 58235 & 9112 & 8299 & 1631 & 124484 & 9079 & 20413 & 153976 & 6400 & 24.06 \\
5 & 54086 & 11992 & 4149 & 1514 & 128633 & 10593 & 32405 & 171631 & 8000 & 21.45 \\
6 & 52011 & 15005 & 2075 & 1456 & 130708 & 12049 & 47410 & 190167 & 9600 & 19.80 \\
7 & 50974 & 18153 & 1037 & 1427 & 131745 & 13476 & 65563 & 210784 & 11200 & 18.82 \\
8 & 50455 & 21441 & 519 & 1413 & 132264 & 14889 & 87004 & 234157 & 12800 & 18.29 \\
9 & 50196 & 24872 & 259 & 1406 & 132523 & 16295 & 111876 & 260694 & 14400 & 18.10 \\
10 & 50065 & 28452 & 130 & 1402 & 132653 & 17607 & 140328 & 290678 & 16000 & 18.16 \\
\hline
\end{tabular}




\section{Conclusions}

Technical systems lifetime assessment is very complex and responsible task. Practically, it is not possible to precisely define the lifetime assessment parameters but only to give their estimation regarding the precisely defined technical system working conditions.

In this paper, two models for analyzing the tractor lifetime assessment are presented. Models are presented on the theoretical level but are developed thorough the case study. The first one is theoretical and it is based on reliability theory and the other one is special and is based on the ASABE standards. This standard uses empirical data and data about the working conditions, working regimes to give the estimated period of tractor usage. Results show that reliability theory confirms the results and their tendencies obtained by the ASABE standards. In this way, both models are verified. This is of a great practical contribution since one of the models is of a practical and the other of the empirical nature. Conclusions can be summarized in the next two statements: reliability and availability are decreasing through the time while the maintenance expenses are increasing. For each and every machine and working environment, the moment when the reliability as intense decrease and expenses intense increase, can be determined based on the proposed model. Results show that these two moments are very close to each other.

\section{Acknowledgements}

The authors wish to thank to the Ministry of education and science of Republic of Serbia for financing the TR 31051, and TR 33001 Projects.

\section{References}

ASABE (2006). Standards ASAE EP496.3, 2006, Agricultural Machinery Management Data, ASABE, St. Joseph, MI, pp. 333-338

ASABE (2009). Standards ASAE D497.6, 2009, Agricultural Machinery Management Data, ASABE, St. Joseph, MI, pp. 339-346
Dalmiş I S, Tezcan O \& Eruslu S Ö (2017). Fatigue life enhancement of three point hitch system brackets in the garden series Tractors. Journal of Agricultural Sciences 23(2): 185-194

Ebramhimipour V \& Suzuki K (2006). A synergetic approach for assessing and improving equipment performance in offshore industry based on dependability. Reliability Engineering and System Safety 91(1): 10-19

Ekinci Ş \& Çarman K (2017). Effects of some properties of drive tires used in horticultural tractors on tractive performance. Journal of Agricultural Sciences 23(1): 84-94

Mileusnic Z I, Petrovic D V \& Đevic M S (2010). Comparison of tillage systems according to fuel consumption. Energy 35(1): 221-228

Miodragovic R, Tanasijevic M, Mileusnic Z \& Jovancic P (2012). Effectiveness assessment of agricultural machinery based on fuzzy sets theory. Expert Systems with Applications 39(10): 8940-8946

O’Connor P D T \& Kleyner A (2012). Practical Reliability Engineering. Fifth edition, John Wiley \& Sons Ltd, West Sussex, United Kingdom

Plessis C (2007). Replacement of earthmoving equipment at surface coal mining operations in South Africa. Research report, Gordon Institute of Business Science, University of Pretoria, Pretoria

Polovina D, Ivkovic S, Ignjatovic D \& Tanasijevic M (2010). Remaining operational capabilities evaluation of bucket wheel excavator by application of expert's assessment method with empirical correction factor. Structural Integrity and Life 10(1): 31-42

Previati G, Gobbi M \& Mastinu G (2011). Multiobjective-reliability-based optimisation of a farm tractor front axle suspension. International Journal of Heavy Vehicle Systems 18(3): 257-271

Tomantschger K W, Petrovic V D, Golubovic Đ Z \& Mileusnic I Z (2011). Differential equation model for durability of the tractor's engine with application to the model Massey Ferguson 8160. African Journal of Agricultural Research 6(18): 4385-4391

Weibull W A (1951). Statistical distribution function of wide applicability. Journal of Applied Mechanics 18(3): 293-297 